\title{
As Narrativas Históricas Escolares e suas Matrizes de Referência
}

\author{
André Victor Cavalcanti Seal da Cunba ${ }^{1}$
}

\section{RESUM0}

Neste artigo busca-se analisar a estrutura discursiva das narrativas para identificar as matrizes historiográficas que servem de referência na sua transposição didática. A investigação teve como campo os ciclos finais do ensino fundamental $\left(3^{\circ}\right.$ e $4^{\circ}$ Ciclos) de quatro escolas da rede citada. Elegemos como sujeitos cinco (5) professores, todos graduados em licenciatura plena em História. Para a coleta dos dados, utilizamos entrevistas (iniciais, durante as observações de sala, e finais) e observações em sala, ambas áudio-gravadas e convertidas em peças protocolares, constituindo nosso corpo documental. Diversas matrizes historiográficas participaram das (re)invenções, apresentando-se muitas vezes em estruturas mistas. Não obstante, percebe-se uma preponderância do Marxismo. Percebemos que o repertório de saberes históricos escolares formados na graduação e nos anos iniciais da profissionalização representou um núcleo duro da transposição didática interna.

Palavras-Chave: Ensino de História, Narrativas Históricas Escolares, Transposição Didática.

Neste artigo estamos nos propondo a socializar um dos aspectos enfocados em nossa dissertação de Mestrado. Nela investigamos as apropriações das narrativas históricas escolares pela prática pedagógica de cinco professores de História da rede municipal de Recife. Deitar o olhar investigativo na sala de aula significa, para nós, acessar a "caixa preta" do ensino de História, o lócus onde a História escolar é efetivamente ensinada. Algumas questões nortearam nossa empresa, que objetivava analisar as apropriações das narrativas históricas pela prática pedagógica dos docentes. Neste texto analisaremos as opções dos

\footnotetext{
1 Mestre em Educação pela UFPE. Professor de Prática de Ensino de História da Universidade Federal de Pernambuco. E-mail-andrevseal@yahoo.com.br.
} 
professores no que tange às matrizes históricas. Na "guerra de narrativas" estabelecida ao nível da noosfera ${ }^{2}$, caracterizada pela disputa para se definir os novos saberes de referência a serem transpostos, procuramos identificar as apropriações das matrizes historiográficas presentes nas narrativas históricas escolares reinventadas nas salas de aula.

Entendendo a categoria "narrativa histórica" como uma delimitação dentro do saber histórico escolar, identificamos nos discursos ministrados em sala pelos sujeitos de nossa investigação a (re)invenção de vinte e sete narrativas históricas escolares, sendo consideradas enquanto unidades discursivas, portadoras de significado e coesão interna que as singularizam.

Entre as narrativas encontradas, consideramos que duas traziam elementos que permitiam caracterizar uma apropriação da matriz dita positivista que, neste trabalho, estamos optando por denominá-la, como convencionalmente tem ocorrido no meio historiográfico, pelo sinônimo de "tradicional". Na primeira delas, re-inventada por \$4, a temática versou sobre a "Tradição da Cultura grega". 0 vocábulo "tradição" nos pareceu bastante sugestivo, por se tratar de uma apropriação da matriz cuja insígnia pesa justamente a marca de tradicional. A narrottiva é transcrita no quadro através de um esquema, sendo apresentados elementos da arte grega e as áreas de sua cultura, como poderemos ver nestes trechos:

\section{Arte Grega \\ $\rightarrow$ Proporção Humana Esculturas em Mármore \\ Representação da Figura Humana}

\footnotetext{
2 Essaéconsiderada o espaço imaginário de encontro dos representantes do sistema de ensino com os representantes da sociedade. Da noosfera participariam diversos agentes, tais como professores, didatas, pedagogos, acadêmicos, autores de livros didáticos e políticos envolvidos com questões da educação escolar (PAIS, 2001; SANTOS et al, 2003). Para ASTOLFI e DEVELAY (1991, p. 48), a noosfera representaria um círculo de pensamento intermediário entre a produção de conhecimento acadêmico e a atividade de ensino. Na noosfera dar-se-ia, ao estilo habermaniano, o processo de enfrentamentos, conflitos de interesse, negociações, acordos, soluções ou indicativos de soluções entre os sujeitos envolvidos na dinâmica do sistema de ensino e suas inter-relações com a sociedade. É nela que se processa a seleção dos elementos do saber sábio que integrarão as propostas curriculares, os livros didáticos, etc. Ela é a grande instância reguladora dos fluxos de saber sábio, constituindo-se no "centro operacional del proceso de transposición" (CHEVALLARD, 1991, . 34).
} 
Áreas da Cultura Grega:

Filosofia - saber crítico sobre a realidade

Teatro - origem nas festas dionisíacas

Tragédia e Comédia

Tragédia - História com teor moral

Comédia - crítica aos costumes da época

$\left(\$ 4^{3}, 1^{\circ}\right.$ ano do $4^{\circ}$ ciclo, Prot.4).

Analisando seus elementos constitutivos, observamos que esta é uma configuração disciplinar há muito transposta, talvez estando presente desde o momento de constituição da História enquanto disciplina escolar no Brasil. No entanto, consideramos que esta narrativa remete muito mais a uma apropriação de saberes tradicionais ou tradicionalmente transpostos do que propriamente uma "narrativa tradicional", no sentido de trazer em seu bojo todas as características heróicas, nacionalistas, factuais e de centralidade de aspectos políticos. Uma versão assim, de uma história da nação, com suas finalidades voltadas para formar cidadãos conformados à estrutura social vigente e integrantes passivos do Estado, nos pareceu a grande "ausência" nas aulas observadas. Pelo menos no que tange aos sujeitos da pesquisa, narrativas positivistas-tradicionais não foram encontradas em seu estado "puro", o que nos indica um elemento importante. 0 processo de crise disciplinar porque passou a disciplina nos últimos 25 anos tem promovido uma renovação nas estruturas dos saberes. 0 questionamento de narrativas do tipo "tradicional", que adquiriu por vezes tonalidades pejorativas a ponto da "satanização", pode estar levando ao seu abandono como configuração disciplinar e, portanto, como matriz de referência para os saberes históricos escolares efetivamente ensinados. A questão aqui é de saber se se trata de uma ruptura, no sentido de ser essas narrativas completamente descartadas ou se elas adquiriram uma sobre-vida, comportando ou integrando re-elaborações com outras matrizes.

Até pelo menos a década de 1950 a História escolar tradicional, cuja matriz de referência na Historiografia era a dita "positivista", mantinha-se em pleno vigor. Isso

3 Vale salientar que, para fins da preservação da identidade dos sujeitos, estes foram codificados em Sujeito 1 (S1), Sujeito 2 (S2), Sujeito 3 (S3), Sujeito 4 (S4), Sujeito 5 (S5). Prot. representa no texto a abreviação de "protocolo". 
se entendermos os campos de saber acadêmico e escolar como sendo de tal forma atrelados hierarquicamente que as transformações ocorridas no primeiro levem concomitantemente, em "tempo real", a mudanças no segundo. Em nossa investigação, não encontramos narrativas reinventadas pelos sujeitos da pesquisa que pudessem ser consideradas, stricto sensu, como pertencentes a esse fluxo transpositor, que engendrou um viés positivista-nacionalista, com culto dos vultos da nação no ensino de História em nosso país.

Em síntese, as apropriações consideradas "tradicionais" diferem em muito da História tradicional de viés nacionalista que prevaleceu por muito tempo no ensino da disciplina no Brasil. A análise das narrativas históricas reinventadas pela prática pedagógica desses cinco sujeitos não nos autoriza a "encaixá-los" em generalizações. Ao contrário do que se poderia esperar, encontramos não uma história positivista-nacionalista, mas saberes tradicionalmente transpostos e que, em sua maioria, têm alcançado uma sobrevida através de uma forma mista, quase uma "mutação didática". Antes porém, precisamos tratar das apropriações a uma outra matriz de referência, que engendram as narrativas marxistas escolares.

\section{As Narrativas Marxistas Escolares}

No total das vinte e sete unidades narrativas identificadas, doze podem ser caracterizadas de "marxistas", pois trazem em seu bojo elementos de apropriação desta matriz de referência. Selecionamos duas narrativas para ilustração de nossas análises. Elas dão uma idéia panorâmica do que encontramos. A primeira delas versa sobre o nascimento de uma nova classe social (a burguesia), que levou ao surgimento de um outro sistema econômico: o capitalismo. Sugestivo não?

Alguns trechos sintetizam bem os elementos característicos do marxismo.

Então, com essa transformação, com essa mudança de ressurgimento das cidades, a sociedade também se transforma. Então a primeira coisa é o deslocamento do eixo econômico do campo para a cidade. (...) A economia era rural e girava em torno da agricultura principalmente e, pouco a pouco, passa a girar em torno do comércio e do artesanato. Isso vai fazer com que a estrutura social se modifique. 
Começa a surgir um novo grupo social, no caso a burguesia. (...) Mas esse grupo vai surgir aqui no séc. XII, XIII, e vai crescer e dar bastante trabalho ao longo dos séculos. Então a estrutura da sociedade ela vai se modificar de forma considerada porque você tem durante a idade média, você tem o Clero, que são funcionários da igreja, a Nobreza e os Servos.

(S5, $2^{\circ}$ ano do $3^{\circ}$ ciclo, Prot.2).

Vemos aqui a centralidade do aspecto econômico, não mais do políticoadministrativo. Os sujeitos do processo não são figuras de destaque, personalidades heróicas relacionadas ao Estado Nacional, mas um ente abstrato, uma categoria teórica, que são as classes sociais. Apesar de não estar presente a expressão literal "classe", sendo substituída por "grupo", são elas que ocupam a posição de sujeitos históricos no enredo da narrativa. A inserção do vocábulo "grupo" e não "classe" talvez revele um certo cuidado do docente não parecer dogmático ou em não caracterizar uma certa adesão ao estruturalismo-ortodoxo do marxismo. Nele também a transformação histórica (surgimento da burguesia) é explicada a partir da mudança no eixo das atividades produtivas (deslocamento do campo para a cidade). Encontramos em outro trecho a mesma perspectiva:

...Com o passar dos séculos, a partir justamente do desenvolvimento da burguesia, pelo desenvolvimento das atividades urbanas, é que a terra foi perdendo a importância diante do dinheiro. (...) Ser nobre é uma condição pra ter terra e ter terra significa ser nobre. Então o valor maior na idade média era a terra. (...) ...quando esse eixo passa do campo pra cidade é isso aqui, o dinheiro passa a ser mais importante do que a terra.

(S5, $2^{\circ}$ ano do $3^{\circ}$ ciclo, Prot. 2$)$

Nele o viés explicativo do processo histórico é o clássico binômio marxista da infra-estrutura para a super-estrutura. A mentalidade burguesa de valorização da riqueza móvel em detrimento da concepção medieval de valorização da terra como insígnia de status social encontra supremacia pelo fortalecimento da atividade econômica do comércio.

Entretanto, tomamos o cuidado em demonstrar a diferença entre as narrativas 
e os sujeitos que dela se apropriam. Em muitos casos não existe distância, e sim um abismo. Incoerência? Acreditamos que não. Ao que tudo indica, não só as vinculações teóricas interferem na apropriação dos saberes para a reinvenção das narrativas. CHARTIER (1998) em análise que enfocava a relação dos saberes práticos e teóricos mobilizados pelos professores na atividade docente se deparou com a adoção de procedimentos didático-pedagógicos referentes a matrizes teóricas díspares e até mesmo antagônicas. Não obstante, a autora afirma que

...o que poderia aparecer, de um ponto de vista teórico, como a coexistência heteróclita de atividades relacionadas a modelos incompatíveis (tratar a escrita como gesto motor/ como código simbólico/ como saber linguístico específico), aparece, do ponto de vista dos "saberes da ação", como um sistema dotado de uma forte coerência pragmática... (CHARTIER, 1998, p. 76).

Isso porque as preocupações dos professores estariam voltadas para 0 atendimento das demandas relativas à prática pedagógica, aos desafios e enfrentamentos da ação. Acreditamos, desta forma, que os sujeitos se servem do repertório de saberes adquiridos em espaços diversos, como o da formação e do fazer docente. Ao que parece, o processo de apropriação não exige fidelidade a uma determinada matriz historiográfica, seguindo uma lógica pragmática, na qual os saberes são chamados a participar do triângulo didático na medida que são considerados úteis para aquele momento. Portanto,

Quem é responsável por essa atribuição de sentido na história escolar? 0 professor de História que, para isso, não segue um modelo pré-definido, geral ou estrutural que oriente a transposição: a história escolar é reinventada em cada aula, no contexto de situações de ensino específicas onde interagem as características do professor (e onde também são expressas as disposições oriundas de uma cultura profissional), dos alunos e aquelas da instituição (aí podendo ser considerada tanto a escolar como o campo disciplinar), características essas que criam um campo de onde emergem a disciplina escolar (MONTEIRO, 2002, p. 103-104).

Compreendida a lógica e coerência pragmática que caracteriza 0 trabalho transpositor dos docentes, podemos voltar à análise dos elementos presentes na 
narrativa marxista escolar. As nossas constatações nos permitem realizar algumas reflexões. Ainda encontramos nos sujeitos da pesquisa o marxismo como a matriz de maior preponderância enquanto referência para as narrativas reinventadas na prática pedagógica. Não obstante, conceitos-chave anteriormente utilizados em larga escala na dieta dos saberes sequer são mencionados nas aulas. A grande ausência com relação às narrativas marxistas escolares foi a categoria de "modo de produção". Em MUNAKATA (2001, p. 280), podem ser encontrados os conceitos que estruturavam a organização dos conteúdos em livros didáticos de História na década de 1980, cujo referencial adotado era o "marxismo".

Os conceitos são: trabalho; meios de trabalho; objetos de trabalho; meios de produção; força de trabalho; forças produtivas; modo de produção; relações sociais de produção; e classe.

Dentre eles o modo de produção dava o norte, representando o eixo na organização dos saberes históricos escolares ao nível da noosfera. Nos discursos de apropriação marxista, não identificamos sua presença, pelo menos de forma explícita.

Assim, observamos que nos sujeitos da investigação a linguagem panfletária, própria de uma apropriação dos anos 80 com seus esquemas rígidos e determinados, se arrefeceu, mas as categorias, conceitos e noções do marxismo permanecem bastante presentes. Isso talvez possa sugerir uma certa superação da versão dogmática sem a ruptura com essa matriz de referência. Consideramos que nas apropriações do marxismo estão presentes três aspectos que caracterizam uma vinculação a este paradigma historiográfico. A presença de transposições de saberes cunhados em suas fronteiras; do enredo ou trama narrativa marcadamente marxista e das categorias, conceitos e noções que integram este referencial teórico. Juntos eles conformam uma criação didática peculiar: as narrativas marxistas escolares.

Se para os agentes da noosfera, o marxismo se arrefece, no que tange à transposição didática interna, pelo menos com relação aos sujeitos de nossa investigação, na disputa discursiva da crise disciplinar, a matriz marxista permanece uma referência hegemônica. 0 que explicaria essa aparente contradição? Nas entrevistas, poderemos perceber que a formação inicial dos 
sujeitos ocorreu na década de 1980 e começo dos anos 90, período em que 0 marxismo gozou de extrema evidência. Obviamente, não estamos defendendo o estabelecimento de uma relação linear entre apropriação de saberes e formação inicial. Isto seria incorrer em um raciocínio bastante simplista. Não obstante, nosso esforço para compreensão foi o de mapear os elementos constitutivos do "núcleo duro" da transposição didática interna, ou seja, aqueles elementos que atuaram como eixo norteador das apropriações. Consideramos que os achados nos possibilitam afirmar com segurança que um deles foi a graduação, o que não equivale advogar a sua exclusividade. Talvez a formação inicial desempenhe o papel de menor preponderância neste núcleo central de saberes. Uma outra variante a ser lembrada pode ser ilustrada com este trecho:

Na verdade é isso, a universidade como ela trabalha, com o sentido de aprofundar alguns temas, ela deixa de fora uma infinidade de temas, que o professor vai ter que se defrontar na sala de aula. E aí o que acontece geralmente é o seguinte, é que o professor na maioria das vezes, fica com o livro didático.

$\left(\mathrm{S} 1, \mathrm{EF}^{4}\right)$.

As minhas aulas, eram preparadas, com base no programa, que existia, que a rede dava para a gente. E em cima dos livros didáticos, como eu te falei. Na época, era Nélson Piletti, dentro daquela história separada. História do Brasil e História geral.

Pesquisador - Em 88, 89?

Sujeito 3 - Em 89. 89.

$(\mathrm{S} 3, \mathrm{EI})$.

Não só na graduação, mas nos anos iniciais da docência, na fase considerada de início da profissionalização docente, saberes são apropriados e passam a representar uma espécie de "repertório de saber" que o professor lança mão diante de qualquer necessidade. Repertório este que possui como ancoragem, como maior repositório, os livros didáticos da disciplina. Vale salientar que não estamos tratando dos "saberes da experiência" - categoria cunhada por TARDIF (2002, p. 52-53) - e sim da apropriação de saberes históricos escolares via prática de ensino. Consideramos que

4 No texto as entrevistas Iniciais e Finais estão sendo abreviadas de "EI" e "EF", respectivamente. 
as apropriações realizadas neste momento de investimento, do início de carreira profissional, podem estar desempenhando forte influência nas narrativas reinventadas durante as aulas observadas.

Entendida a existência do repertório de saber histórico escolar, precisamos deixar clara a posição. Estamos cientes de que sua formação não termina na graduação, nem tampouco nos anos iniciais de profissionalização. Porém acreditamos que nesse dois períodos o investimento de tempo e energia realizados pelo docente no sentido de adquirir saberes de sua disciplina pode impregnar toda a sua trajetória profissional. Estes são dados que nos parecem elucidar a forte presença da matriz marxista nas narrativas históricas (re)inventadas pelos sujeitos de nossa pesquisa. Vemos, assim, elemento importante para evidenciar a noção proposta por Chevallard de "autonomia relativa" dos docentes no processo transpositor. Nem a desconexão completa, que projetaria os professores em um vácuo pedagógico e didático, nem a subserviência de concebê-los enquanto meros transmissores de saberes inventados por outros sujeitos, em instâncias outras. 0 caso das narrativas marxistas é bastante ilustrativo. Ao que parece, o tempo de vida do saber, sua ecologia, obedece à dinâmica geral do processo de produção e transposição, mas também é marcada pelas peculiaridades de cada uma de suas esferas.

\section{Apropriações de Narrativas da "Nova História": Ausência? Inexistênciæ?}

Falta-nos ainda apresentar as apropriações da outra matriz de referência, que vêm se constituindo em uma "terceira via", enquanto possibilidade paradigmática, denominada de "Nova História". Sabemos que a partir de meados da década de 1980, ocorreu um boom dos paradidáticos de História do cotidiano (MUNAKATA, 2001, p. 285), bem como, coleções de livros didáticos que se propunham a transpor saberes considerados mais atuais da historiografia, seja no âmbito da organização de conteúdos curriculares, como coleções da dita "História Temática", em que estariam presentes elementos da Nova História, sejam estritamente relacionadas aos saberes dessa matriz, com coleções supostamente dedicadas a isso, como é o caso da História - Cotidiano e Mentalidades. Dessa forma, consideramos que "estava à disposição do professor um elenco considerável de publicações didáticas e paradidáticas que se apresentavam como vinculadas àquelas tendências" (LIMA e FONSECA, 
2004, p. 67), afirmativa que encontra ressonância nos relatos de nossos sujeitos. S1 dá clara demonstração da visibilidade deste processo:

Até porque 0 livro paradidático, ultimamente vem trabalhando com a história do cotidiano, vem trabalhando com história da mentalidade, história da vida privada, então, são elementos que vão acrescentando para a gente ... as aulas. E uma coisa que eu tenho utilizado muito, são livros de coleções, Toda história, Princípios, essas coleções da FTD, por exemplo...

$(\mathrm{S} 1, \mathrm{EF})$.

Não obstante, das vinte e sete unidades discursivas analisadas, não identificamos nenhuma narrativa que contivesse elementos suficientes para nos permitir considerar exclusivamente a "Nova História" como sua matriz de referência. A temática tratada em sala que mais se aproximou do que poderiaser uma apropriação deste tipo foi abordada por S2 e versava sobre o cotidiano vivido pelos soldados durante a Primeira Guerra Mundial. Nela, a docente trouxe textos contendo diversos relatos de participantes do conflito, que explicitavam posições, óticas, contendo leituras bastante díspares, e até antagônicas, sobre o acontecimento. Os alunos liam os documentos selecionados, após o que ela provocava comparações, pedindo opiniões e realizando análises. Um dos trechos lidos relatava uma experiência nas trincheiras:

Não me lavei, nem mesmo cheguei a tirar a roupa e a média de sono a cada 24 horas tem sido de duas horas e meia. (...) Deitávamos uns juntos dos outros, dividindo os cobertores. Os ratos eram muitos. Um deles aparecia às três da manha, ficou olhando para mim.

(S2, $2^{\circ}$ ano do $4^{\circ}$ ciclo, prot.3)

Observamos que esta narrativa se caracteriza pela inserção do cotidiano na História, mas não uma "História do cotidiano". ou seja, o discurso construído, que se propunha à reinvenção do cotidiano nas trincheiras da Primeira Grande Guerra, não está ancorado em uma narrativa da Nova História, não remetendo a um saber acadêmico que possua como corte epistemológico especificamente essa temática.

Ao contrário do que se poderia apressadamente considerar, a docente mantém nesses relatos sobre o cotidiano, uma vinculação à matriz marxista e 
não à tendência historiográfica "História do cotidiano", que encontra sua inspiração nos Annales. Nessa exposição da docente, não foram detectados elementos do paradigma proposto inicialmente pela perspectiva francesa, como por exemplo categorias teóricas ou uma noção de tempo histórico em que estivesse presente a possibilidade de diversas temporalidades. Agora, no que tangue à inserção de elementos do cotidiano, entendido como descrição do vivido em uma dada época, identificamos uma presença abundante. Em diversas narrativas de vinculação marxista, durante a sua reinvenção, aparecem recortes, fragmentos, de descrições do "como aconteceu", do "como era naquela época", de "como as pessoas viviam naquele tempo".

E aí, uma coisa interessante. Essas muralhas das cidades elas vão, é existir, e as portas também. As portas eram fechadas, vocês já viram aquelas homenagens "fulano recebeu as chaves da cidade", vem a partir disso. As chaves que abrem as portas para ter acesso livre... isso ia até o século XVI, XVII era comum ter essas muralhas de portas que eram fechadas à noite.

$\left(\mathrm{S} 5,2^{\circ}\right.$ ano do $4^{\circ}$ ciclo, prot.2)

A expressão de $\mathrm{S} 5$, ao anunciar o filamento de discurso que seria narrado, definindo-o como uma "coisa interessante", pode ser bastante reveladora do sentido de apropriação. Aqui temos um uso do cotidiano como algo pitoresco, curioso, diferente de nós, como o exótico, dentro de uma perspectiva que chega a ser herodotoniana, com sua narrativa que visava atrair a atenção do público, distraindo e dando prazer.

Em síntese, nada identificou uma vinculação exclusiva à transposição do saber histórico relativo à renovação da historiografia francesa. Não obstante, não estamos decretando a completa ausência de narrativas escolares da Nova História nas re-invenções realizadas pelos professores que participaram de nossa pesquisa. Se nossas análises parassem neste momento, não teríamos percebido certas nuances. Consideramos que um significativo salto qualitativo pode ser dado quando percebemos as apropriações dos docentes para além dessas macro-categorias (Tradicional, Marxista, Nova História) indo ao encontro das estruturas narrativas mistas. 


\section{Para Além das Macro-Categorias: Uma Análise das Estruturas Mistas}

Identificamos diversas narrativas em que sua estrutura lógica apresentava elementos característicos de mais de uma matriz de referência. A partir dessa constatação, forjamos duas categorias empíricas para abrigá-las. A primeira delas foi denominada de narrativas híbridas. A noção de hibridismo remete à idéia de criação peculiar que, derivada de entes diferentes, não corresponde às partes que a engendram. Representa não uma síntese no sentido da dialética hegeleana, mas uma terceira posição. Originada das duas primeiras, não pode ser reduzida a elas.

Nas narrativas híbridas vemos uma espécie de fusão matricial, na qual temos elementos característicos de matrizes históricas diferentes em um mesmo corpo discursivo. Nas análises, o tipo de hibridismo encontrado foi engendrado pela apropriação de saberes tanto da História tradicional, quanto do Marxismo. Ao todo, contabilizamos nove unidades discursivas, cuja estrutura lógica permitia considerá-las como narrativas híbridas do tipo "Tradicional-Marxista". Selecionamos para ilustração esta reinvenção de $S 3$, que versava sobre o processo de instauração da ditadura militar no Brasil com o golpe de 64. Nela, identificamos referências constantes de elementos factuais:

E o golpe militar que se deu em 31 de março e 1 de abril de 64. Nessa... Nesse golpe militar, a primeira coisa que fizeram foi acabar com essas reformas que João Goulart estava desenvolvendo no Brasil. (...) ... a partir do general Mourão Filho, uma tropa de tanques, marchando para a capital do Brasil, que na época era o Rio de Janeiro. E só tinha uma intenção: era depor o presidente e os militares assumir o poder. Quando isso se deu, eles saíram de lá em trinta e um de março. E no primeiro de abril, quando foi ... quando foi informado em cadeia nacional a presidência do Brasil estava vaga, ainda com João Goulart no Rio Grande do Sul, os militares tiveram a preocupação de ir no Congresso Nacional, de intervir no congresso nacional e já declarar vaga a Presidência da República.

(S3, $2^{\circ}$ ano do $4^{\circ}$ ciclo, prot. 1)

0 discurso gira em torno dos acontecimentos que levaram ao golpe, estando presentes elementos factuais expostos na vitrine da narração através de 
uma oralização linear, com ênfase nos fatos políticos. Os sujeitos históricos da trama são, ora líderes dos movimentos em disputa, ora categorias abstratas como instituições, classes ou grupos sociais. A narrativa é em grande medida descritiva, apresentando o passado como ele "realmente" teria acontecido.

Não obstante, o elemento explicativo representa o eixo norteador que costura os fios do enredo. 0 mote que explica o processo de instauração da ditadura pode ser convertido no seguinte esquema: as Reformas de Base (Monopólio do Petróleo; Reforma Agrária; Nacionalização das Empresas; Reforma Bancária) contrariam os Interesses dos Grupos Dominantes, resultando no Golpe de 64.

Como pode ser observado, o viés explicativo é o econômico. São os interesses de grupos (classes) dominantes, seja em nível nacional ou internacional, que promovem a reação contra as mudanças das chamadas Reformas de Base. Categorias marxistas também são inseridas ao longo da narrativa, bem como elementos de crítica ao capitalismo, o que poderia ser entendido como um elemento axiológico que sugere vinculação a esta corrente de pensamento.

Desta forma, nós consideramos que no corpo discursivo dessa narrativa estão fundidas características dos saberes históricos tradicionais e dos saberes marxistas escolares. Categorias como "exploração" e "classe social", somadas a uma ênfase em aspectos políticos, com referências constantes a datas, nomes e acontecimentos, demonstram bem o que estamos denominando de narrativas híbridas tradicional-marxistas.

Vale salientar que a produção dessas estruturas híbridas não ocorre no vácuo, representando um fenômeno que possui sua gênese na noosfera. Em momentos assim é que pode ser percebida a validade da contribuição da categoria "transposição didática" em nosso marco de referência. É a obra iniciada por Chevallard que nos permite perceber a autonomia relativa da apropriação dos saberes pela prática pedagógica de professores, remetendo à concepção de seu trabalho transpositor como conectado a outras esferas. Ao realizar a transposição interna, esta já havia se iniciado em outras instâncias, sem necessariamente participação direta do docente. Se não adotássemos esta teoria poderíamos incorrer no equívoco de conceber as reinvenções como sendo um fenômeno isolado, não relacionando às narrativas a uma perspectiva mais 
ampla, desconectando as apropriações realizadas na transposição didática interna ao trabalho da noosfera.

Dito isso, podemos nos voltar para a análise do outro tipo de estrutura mista identificada: as narrativas ecléticas. A noção de ecletismo remete à idéia de diversidade sem fusão. Nela não temos um produto novo, uma criação original. Não há uma miscelânea de elementos como na híbrida. Estes estão unidos, porém se apresentam bem demarcados. Em nossa investigação, encontramos quatro narrativas que traziam no seu corpo discursivo elementos do Marxismo e da Nova História. Estes se apresentavam de forma quase que segmentada, podendo ser distinguidos os trechos referentes a cada uma delas. Uma narrativa reinventada por $\$ 1$ constitui-se em excelente exemplo. Uma análise dos tópicos colocados no quadro pelo professor durante a exposição nos dá uma boa visibilidade da compartimentação dos saberes históricos das duas matrizes que thes serviam de referência.

Os Europeus precisavam de novas terras.

1. Mentalidades - Imaginavam a terra sendo quadrada.

Imaginavam sereias e serpentes gigantes.

Todo desconhecido é monstruoso.

2. Portugal-nobres + Burgueses, Comerciantes.

3. Ceuta - Controle dos Árabes.

Quando os portugueses dominaram. Os Árabes que traziam mercadorias para vender em Ceuta deixaram de fazê-lo.

4. As Especiarias são temperos - Gosto, Conservante Natural

Nessa época não havia geladeira -0 que fazer para conservar a comida?

5. Aliança comercial - Árabes + Genoveses e Venesianos.

6. Galera - (usava remos)

Galeão (espanhol) + de 100 .

Caravela -

(S1, $2^{\circ}$ ano do $3^{\circ}$ ciclo, prot.2)

Como pode ser observado, os tópicos 1, 4 e 6 representam apropriações da Nova História, enquanto os tópicos 2, 3 e 5 seguem a linha de apropriações ao Marxismo, o que reforça a caracterização de uma estrutura eclética, na qual os 
elementos se encontram concatenados a uma mesma narrativa, mas de forma alguma compõem um todo uniforme. Para usar uma analogia, estas estruturas se aproximam do que seria uma mistura heterogênica no campo da química; apesar de constituir um sistema, sua diversidade é perceptível a "olho nu". No caso da narrativa que nos serviu de ilustração, sua segmentação se assemelha quase à criatura de Dr. Victor Frankstein. Porém, mais uma vez lembramos a lógica pragmática de que se serve o docente para realizar suas apropriaçóes. Fidelidades teóricas são para os pudores/rigores da academia. Já a prática pedagógica é marcada por uma coerência pragmática, pois, objetivando

...atribuir sentido ao que ensina, o professor recorre ao saber acadêmico, em suas diferentes escolas e matrizes teóricas, para buscar subsídios que lhe permitam produzir versões coerentes com seus pontos de vista, e que tenham uma base de legitimidade dentro do campo. (...) ... no saber escolar encontramos muito mais uma síncrese de diferentes matrizes teóricas do que filiações definidas a determinadas correntes (MONTEIRO, 2002, p. 104).

A interrogação que nos inquieta, mobilizando a nossa atenção, é a de buscar compreender a peculiaridade do movimento de apropriação da matriz Nova História. Porque sua inserção se deu apenas via uma forma eclética? Acreditamos que as concepções dos sujeitos, colhidas nas entrevistas, são bastante elucidativas. Vejamos algumas falas:

Eu não tenho assim nenhuma aula, só em cima do cotidiano não. Ele entra como o recheio do bolo. Eu tô dando aula, ai ele entra ... a história cotidiana, ela sempre é feita como o recheio, um algo mais, né? Para enriquecer o processo...

(S1, EF.).

Então é isso que ... agora cumpri a titulo de ilustração. A gente pode trabalhar e tal, porque há aquela coisa da curiosidade e tal, como essas pessoas viviam?

(S5, EF.).

Observamos que as concepções dos sujeitos, apesar das peculiaridades, possuem convergência ao estabelecer uma posição secundária para os saberes oriundos da 
matriz francesa, chegando-se em um caso isolado, à posição de negação de qualquer contribuição. De forma geral, nos professores, encontramos a clara visibilidade de se reservar aos saberes da Nova História um papel coadjuvante. Eles são concebidos enquanto "recheio do bolo", "ilustração", ou submetidos ao talante de categorias macro-estruturais do marxismo.

Nas análises, percebemos que na prática pedagógica sua utilização segue o mesmo padrão. Pequenas referências ao cotidiano na História e apropriações em fatias da História do cotidiano desempenharam a função de "narrativa deleite" e não propriamente de uma narrativa vinculada a um saber plenamente formal. Esse tipo de inserção, que tem caracterizado as apropriações da Nova História, vem cumprindo uma finalidade específica na atividade de ensino dos docentes participantes de nossa pesquisa. Sua inserção no triângulo didático, caminha muito mais no sentido de despertar a curiosidade, mobilizar a atenção dos alunos e alunas, aparentemente distrair, fornecendo entretenimento e prazer aos ouvintes. Este é um papel que não deixa de ter sua importância, na medida em que contribui significativamente para o manejo do grupo-classe, para proporcionar uma interação que poderá levar a momentos de aprendizagem.

Não obstante, consideramos que a virtual contribuição dessa matriz foi pouco explorada durante o período da coleta dos dados. Sua inserção enquanto "narrativa deleite", apesar da reconhecida importância para o manejo da sala, contribuindo com a participação e 0 envolvimento dos alunos nas exposições dos professores, pouco explorou a significativa contribuição destes saberes, como por exemplo, com relação a mostrar a história de grupos marginalizados, uma história da loucura, da sexualidade, da mulher, etc. De forma geral, consideramos que na configuração disciplinar encontrada, a matriz da Nova História desempenhou um papel bastante secundário, limitando sua virtual possibilidade de fornecer inteligibilidade ao real, através da percepção das permanências e rupturas nos processos históricos. Vale neste momento a ressalva de quếnão estamos aderindo à perspectiva de análise a partir da ótica academicista, que de forma truculenta apontaria a configuração disciplinar como sendo ultrapassada.

A análise dos dados nos leva a considerar o tempo peculiar da vitalidade dos saberes históricos escolares reinventados pela prática pedagógica dos docentes. Gozando de autonomia relativa no seu trabalho transpositor, estes sujeitos mobilizam 
saberes que possuem uma temporalidade de vigência própria, respondendo a processos internos, que não estão desconectados de esferas outras, mas que de forma alguma representam um campo desprovido de especificidade. No caso dos professores integrantes da investigação, elementos que podem ter interferido preponderantemente nas apropriações das narrativas históricas foram a formação inicial e os anos iniciais da profissionalização, marcadamente marxistas, os quais parecem ter se constituído em uma espécie de núcleo duro da transposição didática interna. Possivelmente, elementos da Nova História só posteriormente foram sendo incorporados, via processos de formação continuada e apropriações do fluxo transpositor da transposição didática externa.

\section{Referências}

ASTOLFI, Jean Pierre; DEVELAY, Michel. A Didática das Ciências. 2.ed. Campinas: Papirus, 1991.

CHARTIER, A-M. L. L'expertise enseignante entre savoirs practiques et savoirs théoriques. Recherche et Formation. Les savoirs de la pratique: um enjeu por la recherche et la formation. INRP, n. 27, p. 67-82, 1998.

CHEVALIARD, Yves. La Transposición Didática: del saber sabio al saber enseñado. Ed. Aique, 1991.

LIMA e FONSECA, Thaís Nívea de. História e Ensino de História. Belo Horizonte: Autêntica, 2004.

MONTEIR0, Ana Maria Ferreira da Costa. Ensino de História: entre saberes e práticas. Rio de Janeiro: PUC, 2002. Tese (Doutorado em Educação), PUC, 2002.

MUNAKATA, Kazumi. Histórias que os Livros Didáticos Contam, depois que acabou a ditadura no Brasil. In: FREITAS, Marcos César de. Historiografia Brasileira em Perspectiva. São Paulo: Contexto, 2001.

PAIS, Luiz Carlos. Didática da Matemática: uma análise da influência francesa. Belo Horizonte: Autêntica, 2001.

SANTOS, Marcelo Câmara dos; MENEZES, Marcus Bessa; MENEZES, Ana Paula de Avelar Brito. Transposição Didática: elementos para a compreensão desse fenômeno no ensino e aprendizagem de Matemática. Revista Brasileira de Estudos Pedagógicos, 2003.

TARDIF, Maurice. Saberes Docentes e Formação Profissional. Petrópolis: Vozes, 2002. 


\section{The School Historical Narratives and its Matrices of Reference}

ABSTRACT

This research we analyzed the discursive structure of the narratives to identify the historiographical matrices which work as a reference in its didactical transposition. The investigation field covered from the fifth to the eighth grade of primary school in the above mentioned sector. We have elected five (5) teachers as our subjects, all of the graduated in history. To collect the data we worked with interviews (at the beginning, during the classes observations and at the end) and class observations, both of them recorded in audio tapes and converted to protocols, which are our documental corpus. Several historiographical matrices took part in the (re)invention, presenting themselves many times in mixed structures. Notwithstanding, we have noticed a preponderance of the Marxism. We have noticed that the school historical knowledge repertory built during graduation and in the first years of the teacher career represented a hard core of the internal didactical transposition.

Key words: teaching of history; school historical narrative; didactical transposition. 